\title{
Post-stroke bilateral heterotopic ossification: An acute problem with long-lasting consequences
}

\author{
Selin Ozen, MBBS BSc (D), Huma Bölük Şenlikci, MD (D), Oya Ümit Yemişci, MD (D) \\ Department of Physical and Rehabilitation Medicine, Başkent University Faculty of Medicine, Ankara, Turkey
}

\begin{abstract}
Neurogenic heterotopic ossification (HO) is a complication of injury to the central nervous system in which production of lamellar bone within the soft tissues occurs resulting in pain and reduced range of motion (ROM) with eventual ankylosis and loss of functional capacity. ${ }^{[1]}$ Heterotopic ossification is frequently seen as a complication of total hip arthroplasty ${ }^{[2]}$ and in approximately $20 \%$ of traumatic brain injury and spinal cord injury patients. ${ }^{[3]}$ Following stroke, $\mathrm{HO}$ most commonly involves the hip joint ${ }^{[4,5]}$ occurs on the paretic side and rarely on the non-paretic side. ${ }^{[6,7]}$ Bilateral $\mathrm{HO}$ following stroke is even rarer with the most recent cross-sectional study identifying bilateral $\mathrm{HO}$ in only $0.2 \%$ of all stroke patients over a 10 year period. ${ }^{[8]}$ In this article, we present a case of extensive established bilateral $\mathrm{HO}$ of the hips occurring shortly after the onset of stroke.
\end{abstract}

\section{CASE REPORT}

A 77-year-old female patient with a five-month history of stroke, right-sided weakness and left knee contracture presented to our Physical Medicine and Rehabilitation Department. Following the onset of stroke, the patient was initially treated in an intensive care unit (ICU) before being transferred to the

Received: November 04, 2019

Accepted: February 05, 2020

Published online: June 18, 2020

Correspondence: Selin Ozen, MD. Başkent Üniversitesi

Tıp Fakültesi Fiziksel Tıp ve Rehabilitasyon Anabilim Dalı,

06490 Bahçelievler, Ankara, Türkiye.

E-mail: selinhassan@hotmail.com

Doi: $10.5606 /$ ehc. 2020.72081

Citation: Ozen S, Bölük Şenlikci H, Ümit Yemişci O. Post-stroke bilateral heterotopic ossification: An acute problem with longlasting consequences. Jt Dis Relat Surg 2020;31(2):386-389.

\section{ABSTRACT}

Heterotopic ossification (HO) is a complication of injury to the central nervous system in which production of lamellar bone within the soft tissues occurs resulting in pain, reduced range of motion (ROM) and loss of functional capacity. Heterotopic ossification is rarely seen in stroke patients and mostly affects the paretic side. In this article, we present a case of established bilateral HO of the hips soon after stroke onset. A 77-year-old female patient with a five-month history of stroke presented to our rehabilitation clinic. Physical examination revealed sensorimotor aphasia, right-sided hemiplegia, bilateral painful limited ROM of the hips and left knee contracture. An anteroposterior X-ray of the pelvis revealed previously undiagnosed bilateral HO of the hips. The patient and her relatives declined operative interventions. The patient was discussed in the departmental meeting and it was agreed that she would not be able to partake in an active inpatient rehabilitation program. She was discharged with a home exercise plan. This case highlights the importance of HO, of both the paretic and non-paretic side, being included in the differential diagnosis of post-stroke patients presenting with joint pain and reduced ROM, both acutely and in the long-term. This may aid the timely diagnosis and management of $\mathrm{HO}$, a pathology which has detrimental effects on functionality.

Keywords: Bilateral, hemiplegia, heterotopic, hip, ossification, stroke.

neurology ward. Following discharge from the ward, a monoarthritis of the left knee developed. According to the patient's relatives, the patient's knee was evaluated by an orthopedics and traumatology team; however, no details of the evaluation/investigations/ treatment applied are known. To date, the patient had not partaken in a home exercise program or received physical therapy. The patient's past medical history included hypertension, atrial fibrillation, heart failure and a right total knee replacement five years previously due to osteoarthritis. Prior to development of the stroke, the patient was independent of activities of daily living.

Physical examination revealed a Glasgow Coma Score of 12 with motor and sensory aphasia. There 


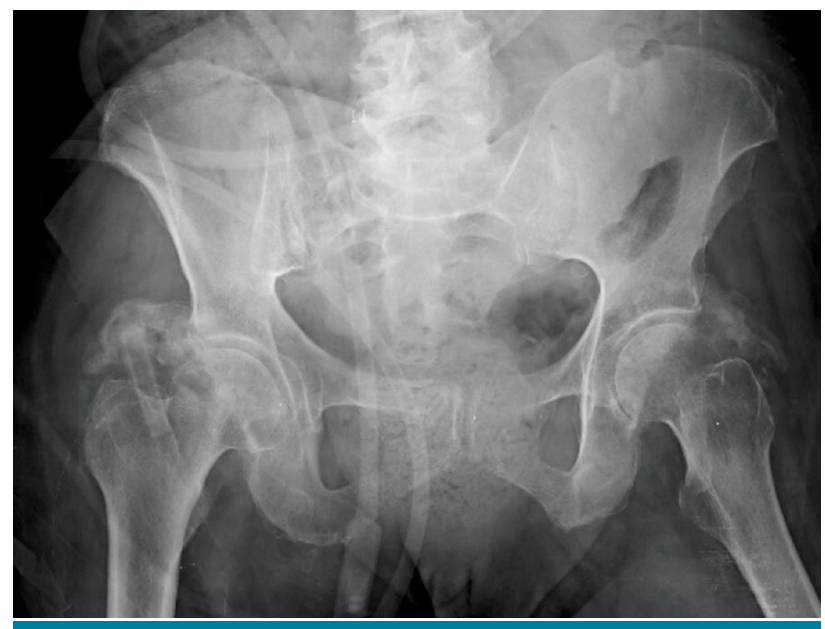

FIGURE 1. Bilateral heterotopic ossification of hips.

was a flaccid paralysis of the right side. No spasticity was detected. The patient was incontinent of urine and feces. Examination of the musculoskeletal system revealed bilateral painful and limited ROM of the hips and left knee contracture. There was no effusion of the joints. The patient's Functional Independence Measure $^{[9]}$ score was 23.

The patient's initial routine blood tests were normal. The erythrocyte sedimentation rate was $69 \mathrm{~mm} /$ hour and the C-reactive protein was $11.4 \mathrm{mg} / \mathrm{L}$. An anteroposterior X-ray of the pelvis revealed extensive bilateral periarticular HO (Figure 1). A two-way bilateral X-ray of the knees revealed a total knee replacement on the right side and extensive osteoarthritis of the left knee (Figure 2). Pharmacological treatment with indomethacin was commenced. The Orthopedics and Traumatology Department was consulted for further management of the bilateral hip $\mathrm{HO}$ and left knee contracture. Initially, arthroscopic debridement of the left knee was recommended; however, the patient's relatives did not consent to the procedure. Due to the patient's limited cooperation, immobility, poor right-sided motor recovery, bilateral limited hip movement and left knee contracture, it was decided that she would gain little benefit from an active inpatient rehabilitation program. The patient was discharged with appropriate analgesia and a home exercise plan with a view to follow-up in the outpatient clinic in a month's time.

\section{DISCUSSION}

Bilateral HO occurring soon after stroke is a subject which remains scarcely covered in the literature. ${ }^{[10,11]}$ A recent cross-sectional study by Cunha et al. ${ }^{[8]}$ of stroke patients admitted to seven rehabilitation centers over a period of 10 years found an annual prevalence of $\mathrm{HO}$ of $1.3 \% .{ }^{[8]}$ Moreover, only $0.2 \%$ of the cases identified had bilateral HO.

In this case, the early diagnosis of $\mathrm{HO}$ of the hips was missed. The early stages of $\mathrm{HO}$ and resultant hip

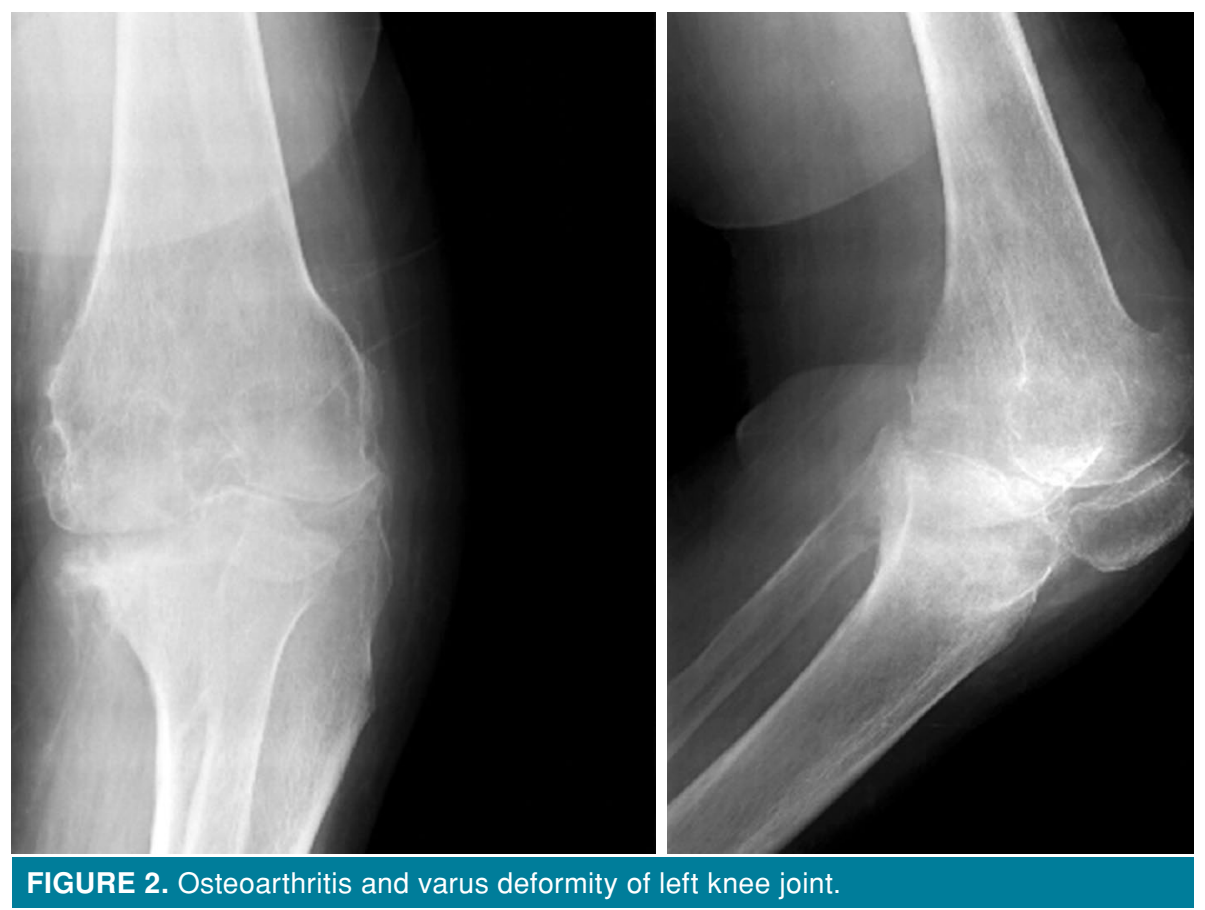


pain may not have been detected due to the patient's poor cognitive function and immobility. For the affected patient, it is crucial that this condition is recognized and diagnosed early so that ankylosis can be prevented by timely treatment. ${ }^{[12]}$ The fact that there was bilateral established $\mathrm{HO}$ by the time the diagnosis was established underlines the fact that awareness on this matter requires further attention, particularly in bed-bound patients in which hip examination may be more challenging. Often, patients initially experience pain and inflammation of the affected joint; therefore, differential diagnoses such as spasticity, monoarthritis and cellulitis may primarily come to mind resulting in a diagnosis of HO being overlooked. ${ }^{[13,14]}$

Moreover, complications associated with HO such as urinary tract infections, deep vein thrombosis and overlying pressure ulceration ${ }^{[15,16]}$ deem early and correct management imperative.

Management of $\mathrm{HO}$ is often targeted at preventing the condition from occurring in unaffected patients. Single-dose radiotherapy or oral nonsteroidal antiinflammatory drugs such as indometacin and maintaining joint ROM post-stroke are used as $\mathrm{HO}$ prophylaxis and treatment. ${ }^{[17]}$ Preliminary studies and case reports on the role of extracorporeal shock wave therapy (ESWT) in the treatment of neurogenic $\mathrm{HO}$ following traumatic brain injury and spinal cord injury suggest that ESWT may reduce pain and increase ROM of the affected joints, ${ }^{[18-20]}$ however, excisional surgery remains the treatment of choice to restore joint mobility. ${ }^{[6,21]}$ In this case, the contracture of the osteoarthritic left knee may have developed secondary to the neurogenic $\mathrm{HO}$ of the hips, as this results in reduced mobility and poor positioning of the patient within bed. Therefore, surgical intervention to the left knee was initially offered to the patient.

Causative factors for the development of $\mathrm{HO}$ remain to be elucidated. Recent studies of stroke patients have concluded that the presence of hemorrhagic stroke/ischemic stroke with hemorrhagic transformation, severity of the initial neurological lesion, presence of spasticity and cognitive impairment are risk factors for the development of HO. ${ }^{[5,7,8,22]}$ Cases of severe $\mathrm{HO}$, such as the case reported here, involve two or more joints and have been associated with ICU stay and the use of invasive ventilation in the acute phase of stroke. ${ }^{[8]}$

This case describes a patient in which the diagnosis of bilateral $\mathrm{HO}$ of the hips was delayed and highlights the importance of $\mathrm{HO}$ being included in the differential diagnosis of post-stroke patients presenting to the Orthopedics Department with joint pain, swelling and reduced ROM both acutely and in the long-term following stroke. Equally, although rare, this case reiterates that development of $\mathrm{HO}$ in the non-paretic side following stroke must be kept in mind to provide timely management of a pathology which is difficult to treat, and can result in ankylosis, to avoid lasting detrimental effects on patient functionality.

\section{Declaration of conflicting interests}

The authors declared no conflicts of interest with respect to the authorship and/or publication of this article.

\section{Funding}

The authors received no financial support for the research and/or authorship of this article.

\section{REFERENCES}

1. Ranganathan K, Loder S, Agarwal S, Wong VW, Forsberg J, Davis TA, et al. Heterotopic Ossification: Basic-Science Principles and Clinical Correlates. J Bone Joint Surg [Am] 2015;97:1101-11.

2. Kaplan FS, Glaser DL, Hebela N, Shore EM. Heterotopic ossification. J Am Acad Orthop Surg 2004;12:116-25.

3. Cipriano CA, Pill SG, Keenan MA. Heterotopic ossification following traumatic brain injury and spinal cord injury. J Am Acad Orthop Surg 2009;17:689-97.

4. Gurcay E, Ozturk EA, Erdem T, Gurcay AG, Cakci A. Heterotopic ossification as rare complication of hemiplegia following stroke: two cases. Brain Inj 2013;27:1727-31.

5. Genêt F, Minooee K, Jourdan C, Ruet A, Denormandie P, Schnitzler A. Troublesome heterotopic ossification and stroke: Features and risk factors. A case control study. Brain Inj 2015;29:866-71.

6. Kocaağa Z, Bal S, Gurgan A. Hemiplegia and heterotopic ossification on the non-paretic extremity: a case report. J Rehabil Med 2007;39:500-2.

7. Pek CH, Lim MC, Yong R, Wong HP. Neurogenic heterotopic ossification after a stroke: diagnostic and radiological challenges. Singapore Med J 2014;55:e119-22.

8. Cunha DA, Camargos S, Passos VMA, Mello CM, Vaz LS, Lima LRS. Heterotopic Ossification After Stroke: Clinical Profile and Severity of Ossification. J Stroke Cerebrovasc Dis 2019;28:513-20.

9. Küçükdeveci AA, Yavuzer G, Elhan AH, Sonel B, Tennant A. Adaptation of the Functional Independence Measure for use in Turkey. Clin Rehabil 2001;15:311-9.

10. Hajek VE. Heterotopic ossification in hemiplegia following stroke. Arch Phys Med Rehabil 1987;68:313-4.

11. Baron M, Stern J, Lander P. Heterotopic ossification heralded by a knee effusion. J Rheumatol 1983;10:961-4.

12. Atik OŞ. Which articles do we prefer to publish? Eklem Hastalik Cerrahisi 2018;29:1.

13. Goldberg MA, Schumacher HR. Heterotopic ossification mimicking acute arthritis after neurologic catastrophes. Arch Intern Med 1977;137:619-21.

14. Jensen LL, Halar E, Little JW, Brooke MM. Neurogenic heterotopic ossification. Am J Phys Med 1987;66:351-63. 
15. Halas, RA, Karuppiah S. Heterotopic ossification of the hip after stroke, Current Orthopaedic Practice 2011;22:E19-E21.

16. McCormack R, McGlone B. Neurogenic heterotopic ossification: a pictorial review. Br J Hosp Med (Lond) 2019;80:707-10.

17. Mavrogenis AF, Soucacos PN, Papagelopoulos PJ. Heterotopic ossification revisited. Orthopedics 2011;34:177.

18. Reznik JE, Biros E, Lamont AC, Sacher Y, Kibrik O, Milanese S, et al. A preliminary investigation on the effect of extracorporeal shock wave therapy as a treatment for neurogenic heterotopic ossification following traumatic brain injury. Part I: Effects on pain. Brain Inj 2017;31:526-32.

19. Reznik JE, Biros E, Sacher Y, Kibrik O, Milanese S, Gordon $S$, et al. A preliminary investigation on the effect of extracorporeal shock wave therapy as a treatment for neurogenic heterotopic ossification following traumatic brain injury. Part II: Effects on function. Brain Inj 2017;31:533-41.

20. Jeon HM, Lee WJ, Chung HS, Yi YG, Yang S, Kim DH, et al. Extracorporeal shock wave therapy to treat neurogenic heterotopic ossification in a patient with spinal cord injury: A case report. J Spinal Cord Med 2019;26:1-4.

21. Yoon BH, Park IK, Sung YB. Ankylosing Neurogenic Myositis Ossificans of the Hip: A Case Series and Review of Literature. Hip Pelvis 2018;30:86-91.

22. Chiu D, Peterson L, Elkind MSV, Rosand J, Gerber LM, Silverstein MD; Glycine Antagonist in Neuroprotection(GAIN) Americas Trial Investigators. Comparison of outcomes after intracerebral hemorrhage and ischemic stroke. J Stroke Cerebrovasc Dis 2010;19:225-9. 